\title{
ESSAY
}

\section{Black Miami's Resiliency: A Photographic Essay}

\author{
Germane Barnes \\ University of Miami, US \\ g.barnes@miami.edu
}

Germane Barnes creates a narrative of Black Miami architecture through the medium of photography.

Keywords: Architecture; Allapattah; Brownsville; Liberty City; Coconut Grove; Overtown; Little Haiti

Black Miami architecture is not unique, in that one can find many examples of scattered-site housing, shotgun-style homes, and low-rise multi-family housing developments across America. However, what is unique to Miami is the littoral urbanism found in the Deep South that requires a significant commitment to the sustainability of local ecologies. The initial housing stock of black migrant labor was composed of single-family shotgun homes and cracker vernacular-type bungalows. Densely organized in the Central Negro District of Miami and Coconut Grove respectively, these historically black architectural typologies revealed many inherent innovations seen in site-specific design. Raised floors and porches, central corridors, and passive cooling are all components of historic black Miami architecture that contemporary Miami has rebranded as climate resiliency and environmentally-friendly design. Unfortunately, today many of the historic architecture remnants are no longer present, and what is left is government-sanctioned housing developments, which reduces the impact and influence of blacks on the build environment. ${ }^{1}$

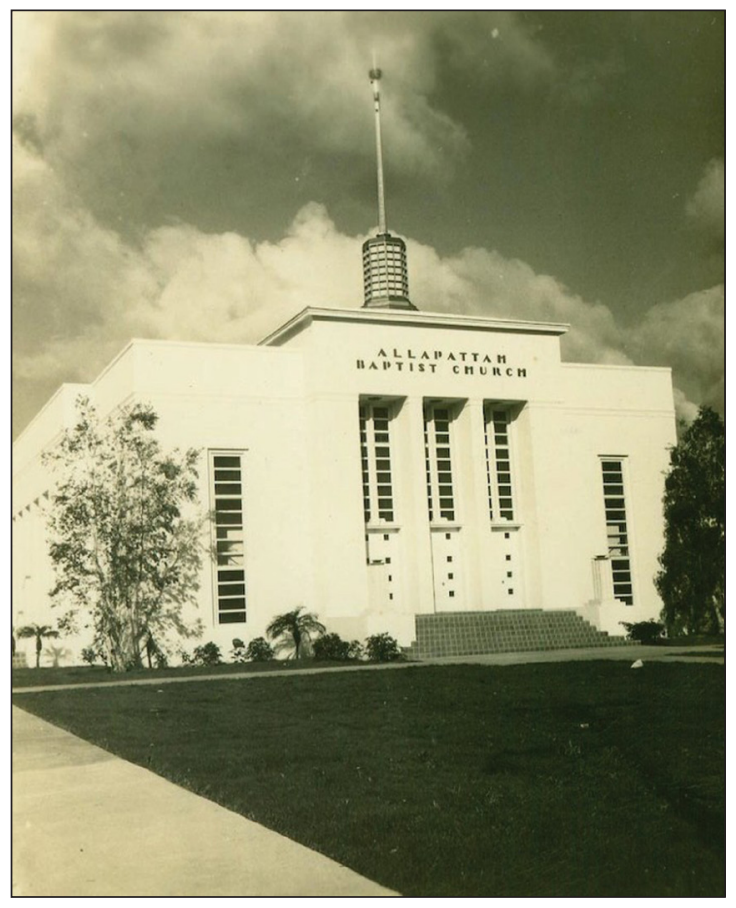

Allapattah Neighborhood. Photo credit floridabaptisthistory.org/2017/08/14/miami-allapattah/.

\footnotetext{
${ }^{1}$ Unless otherwise cited, all photographs are courtesy of the author.
} 


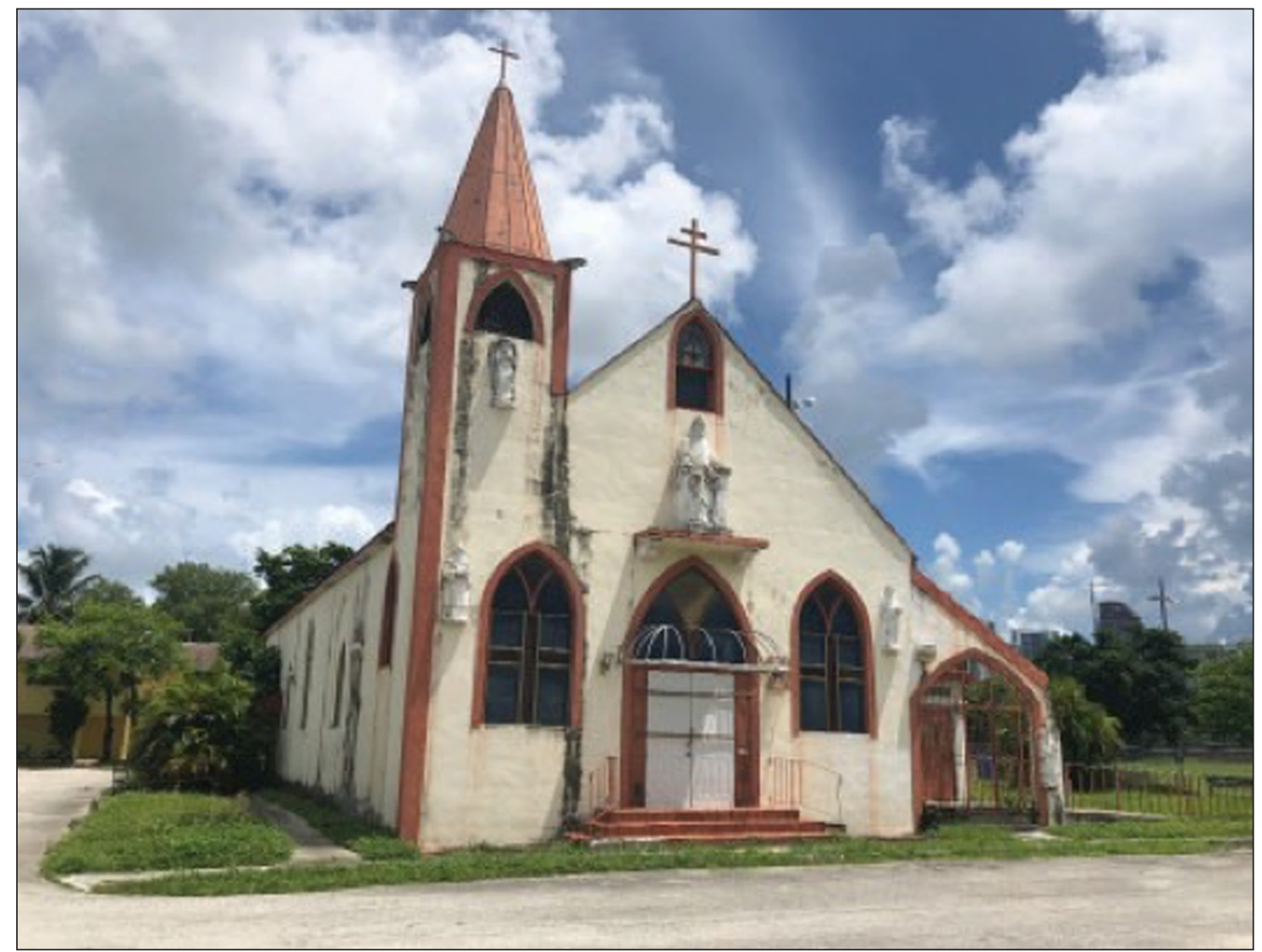

Allapattah Neighborhood, 2019.
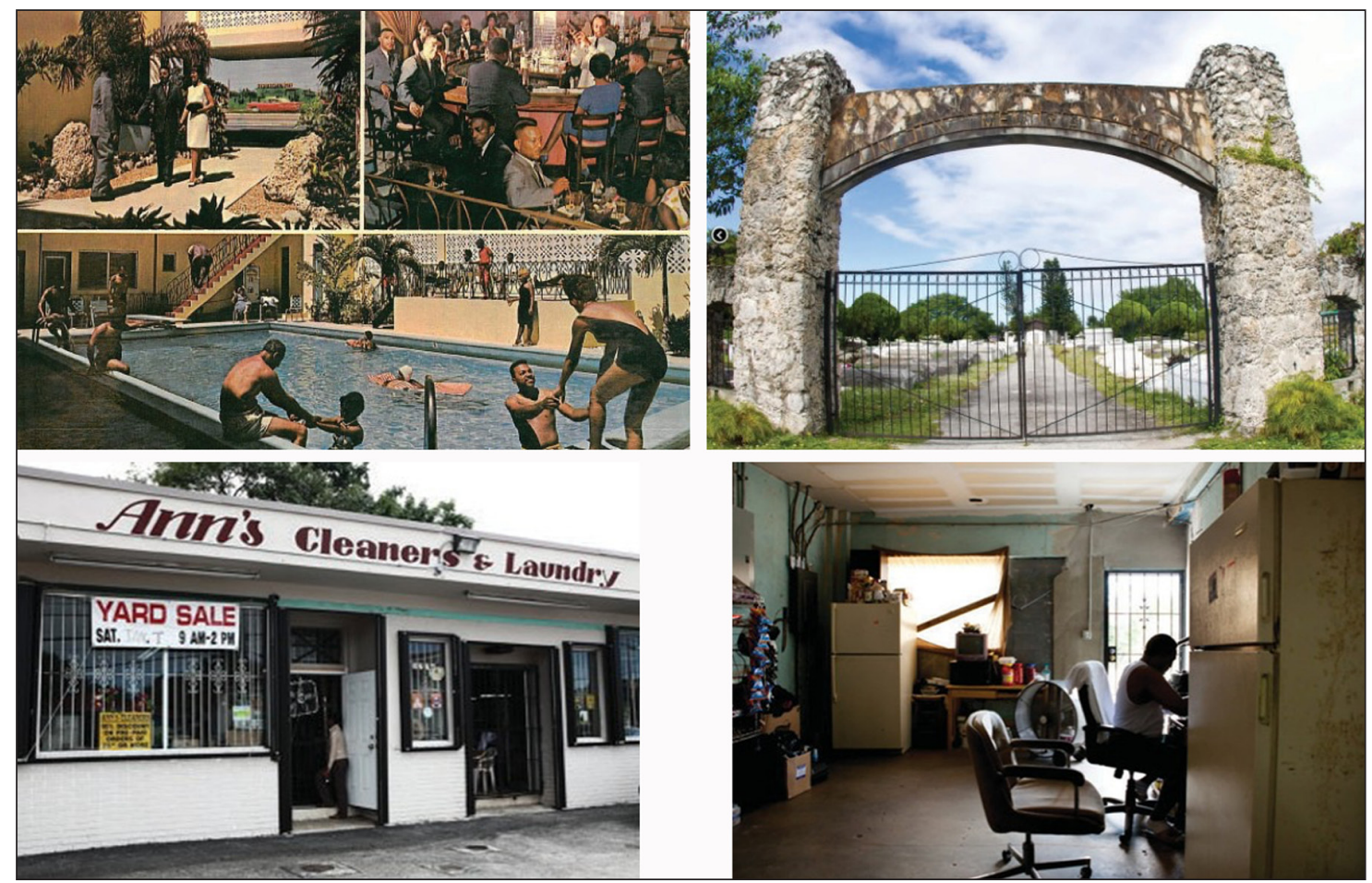

Photos Clockwise L to R.

Hampton House, Brownsville. Photo credit Brownsvillemiami.com/history. Lincoln Memorial Park, Brownsville. Photo credit Brownsvillemiami.com/history.

Interior Residence, Brownsville. Photo credit Brownsvillemiami.com/history. Ann's Cleaners \& Laundry, Brownsville. Photo credit Brownsvillemiami.com/history. 


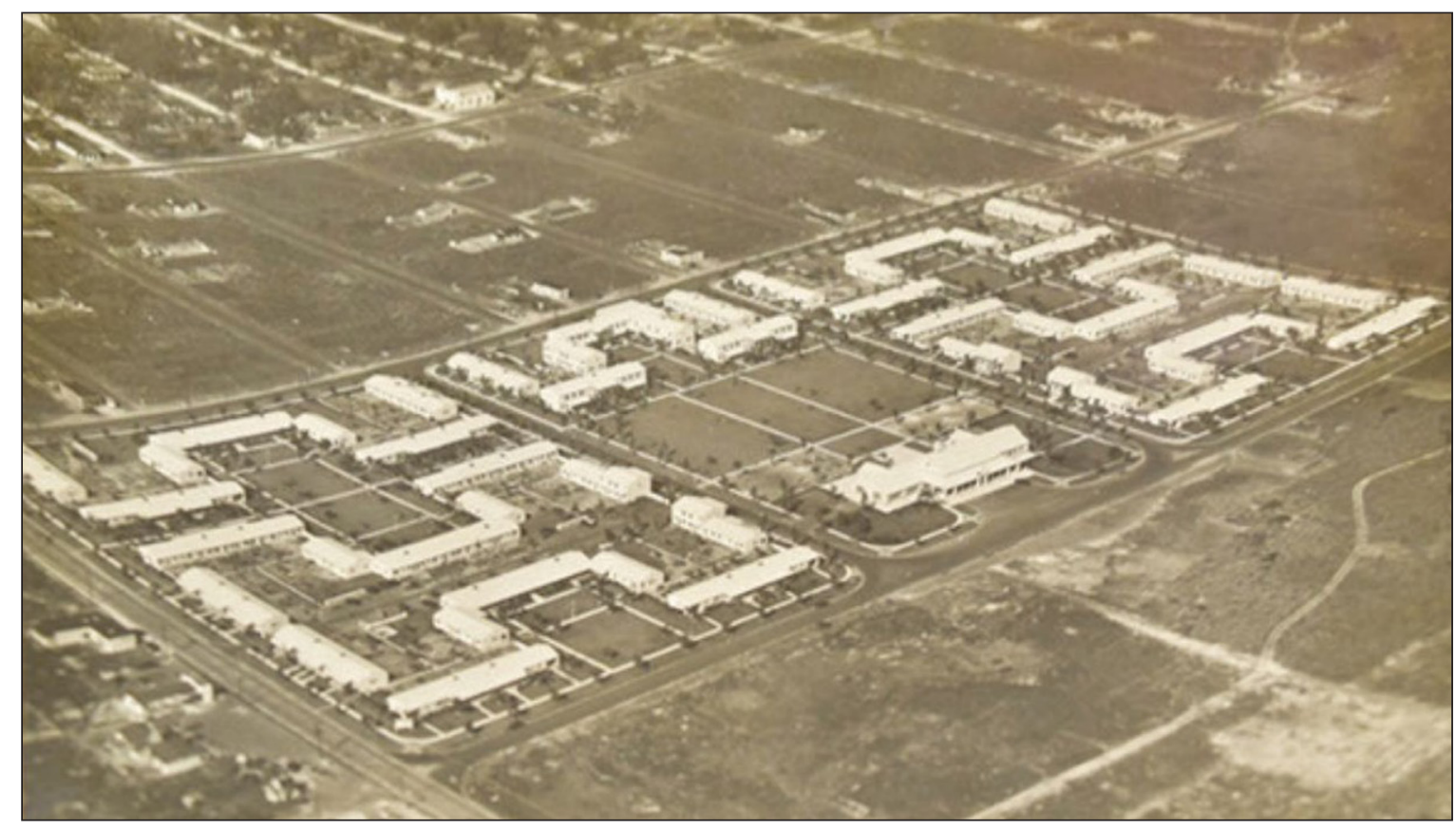

Liberty Square, 1937. Image courtesy of HistoryMiami.

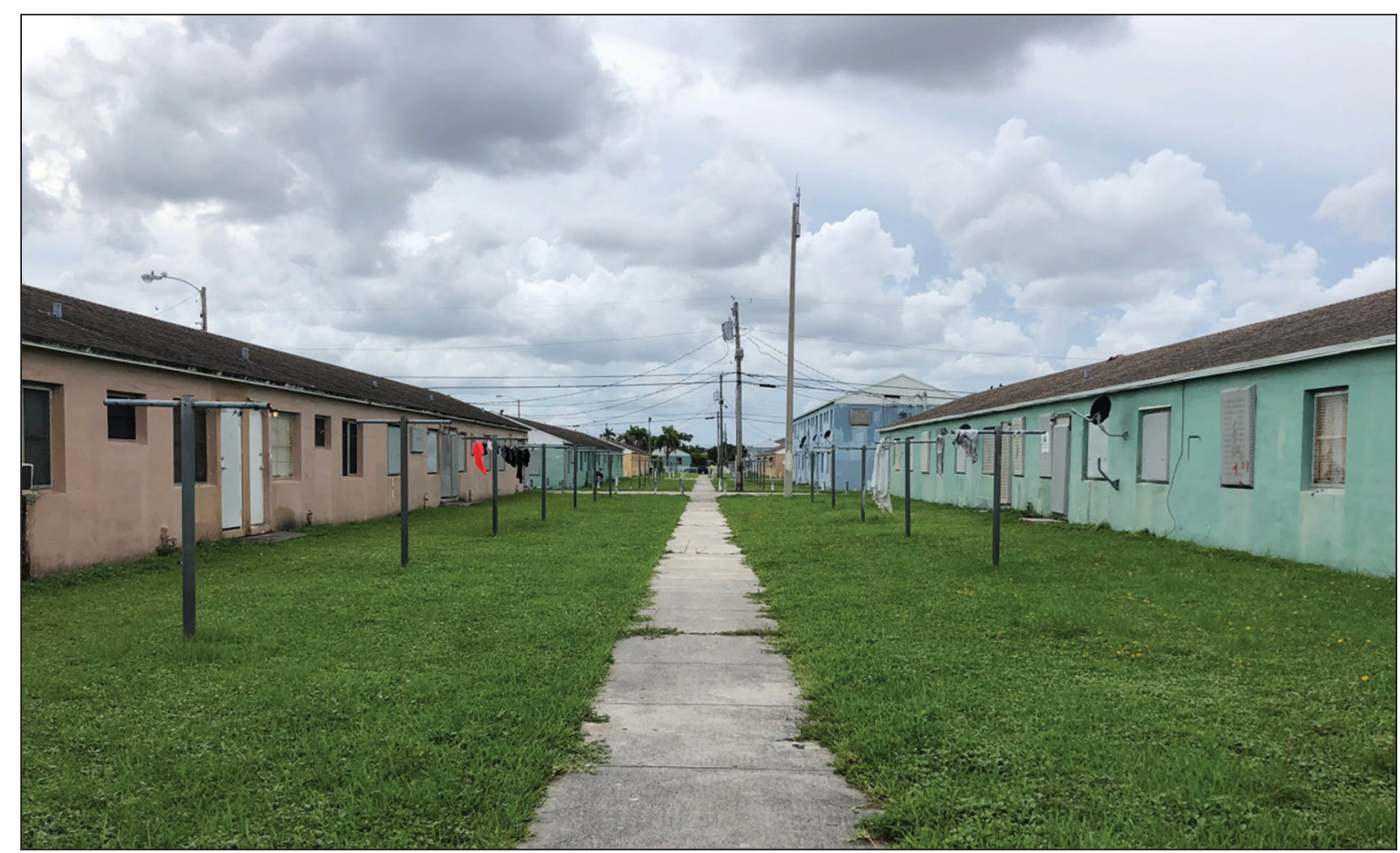

Liberty Square, 2019. 


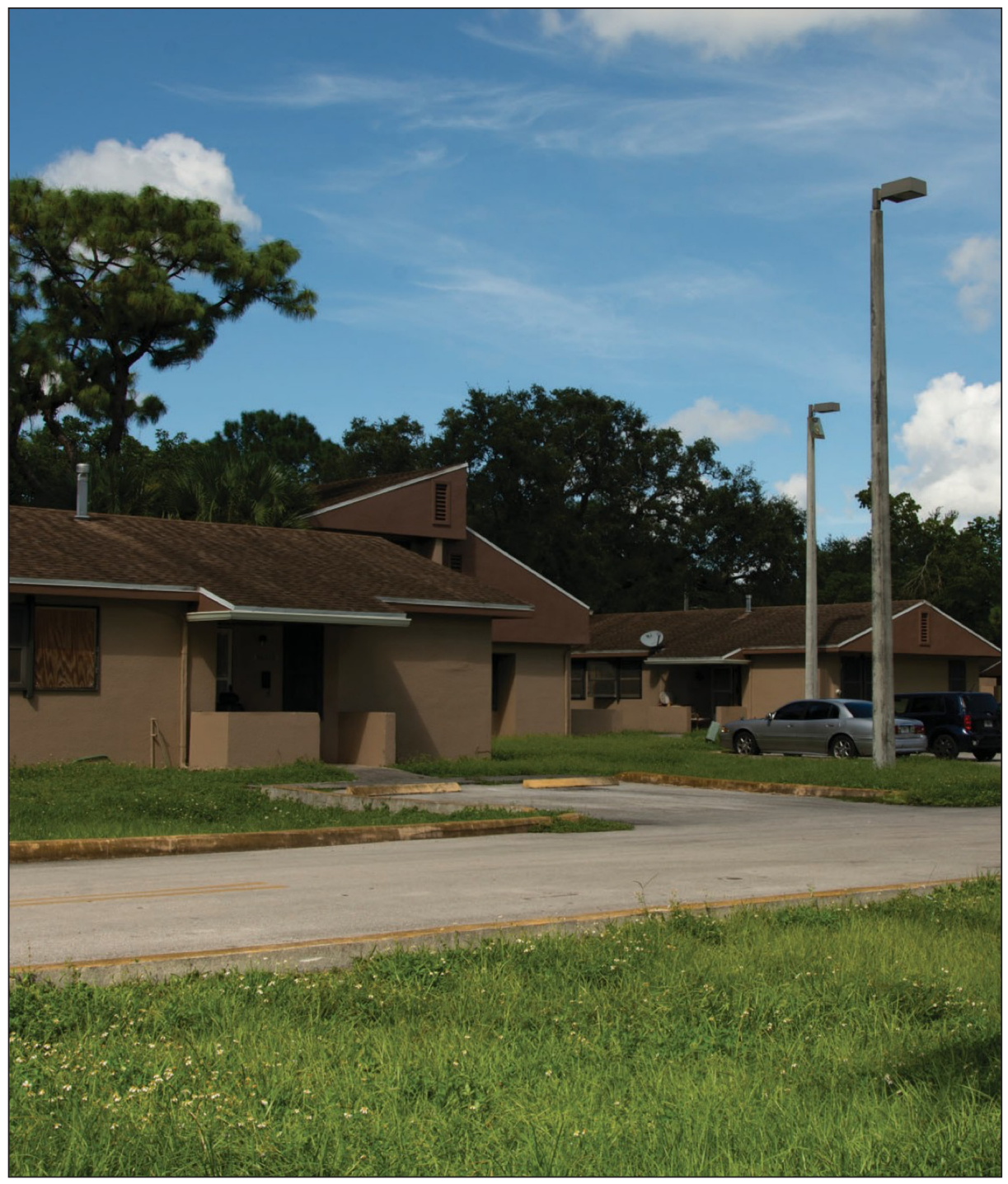

Miami Gardens, 2019.

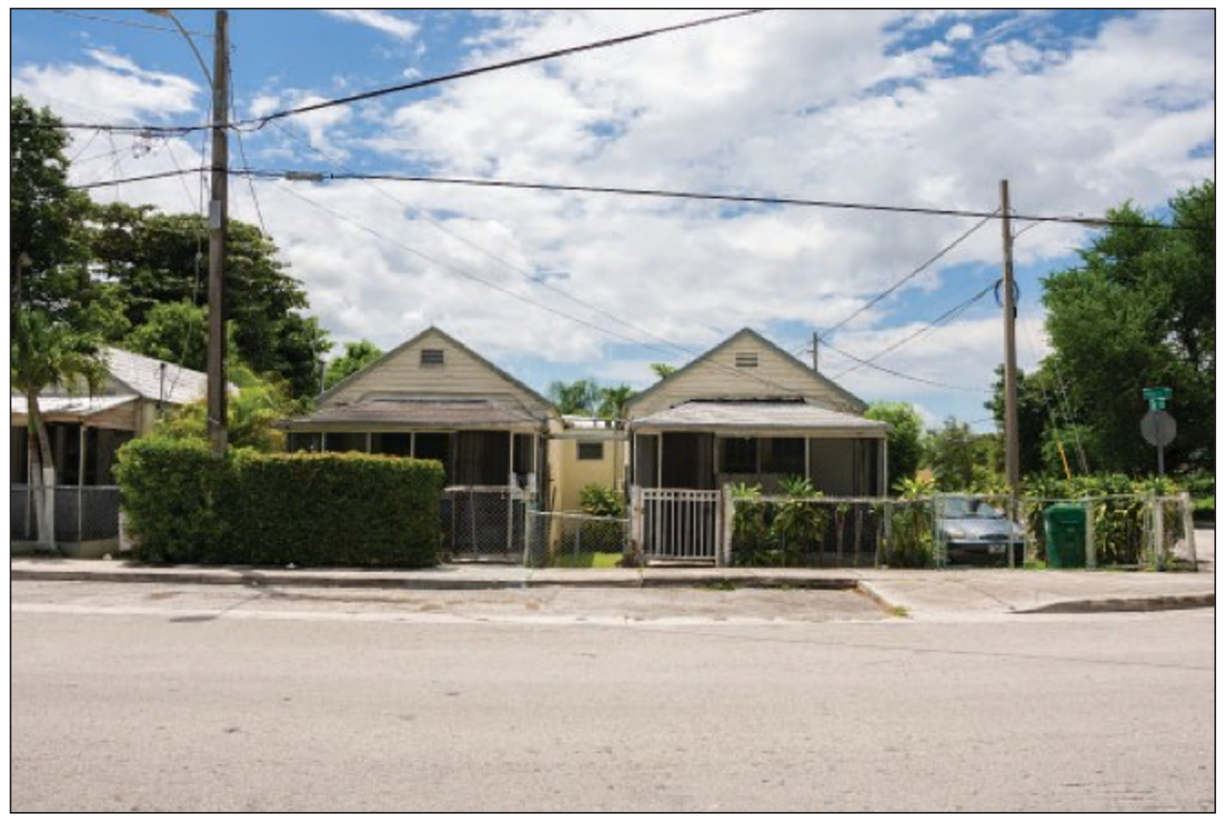

West Coconut Grove, 2019. 


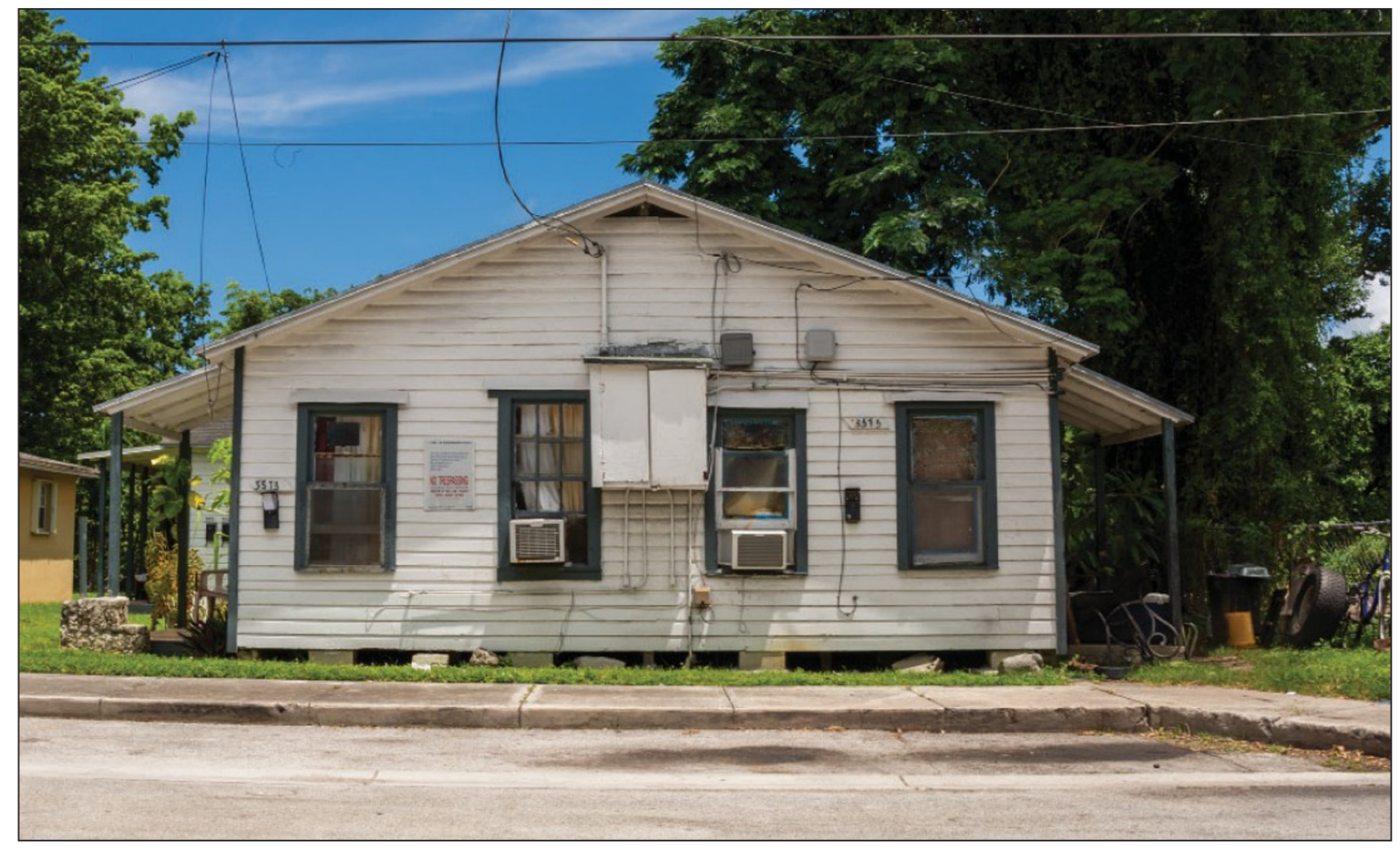

West Coconut Grove, 2019.

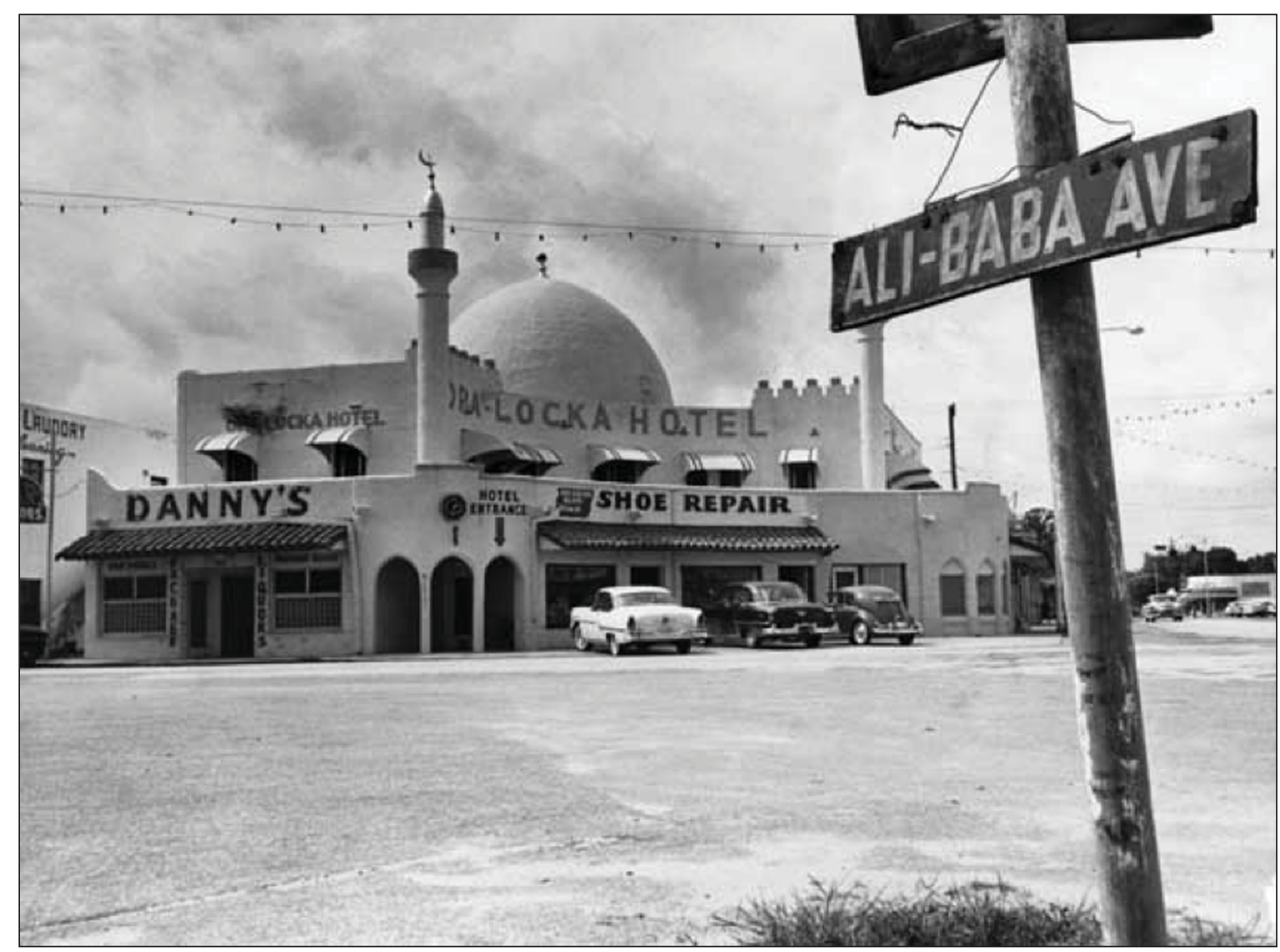

Opa-locka, FL, 1959. Image courtesy of HistoryMiami. 


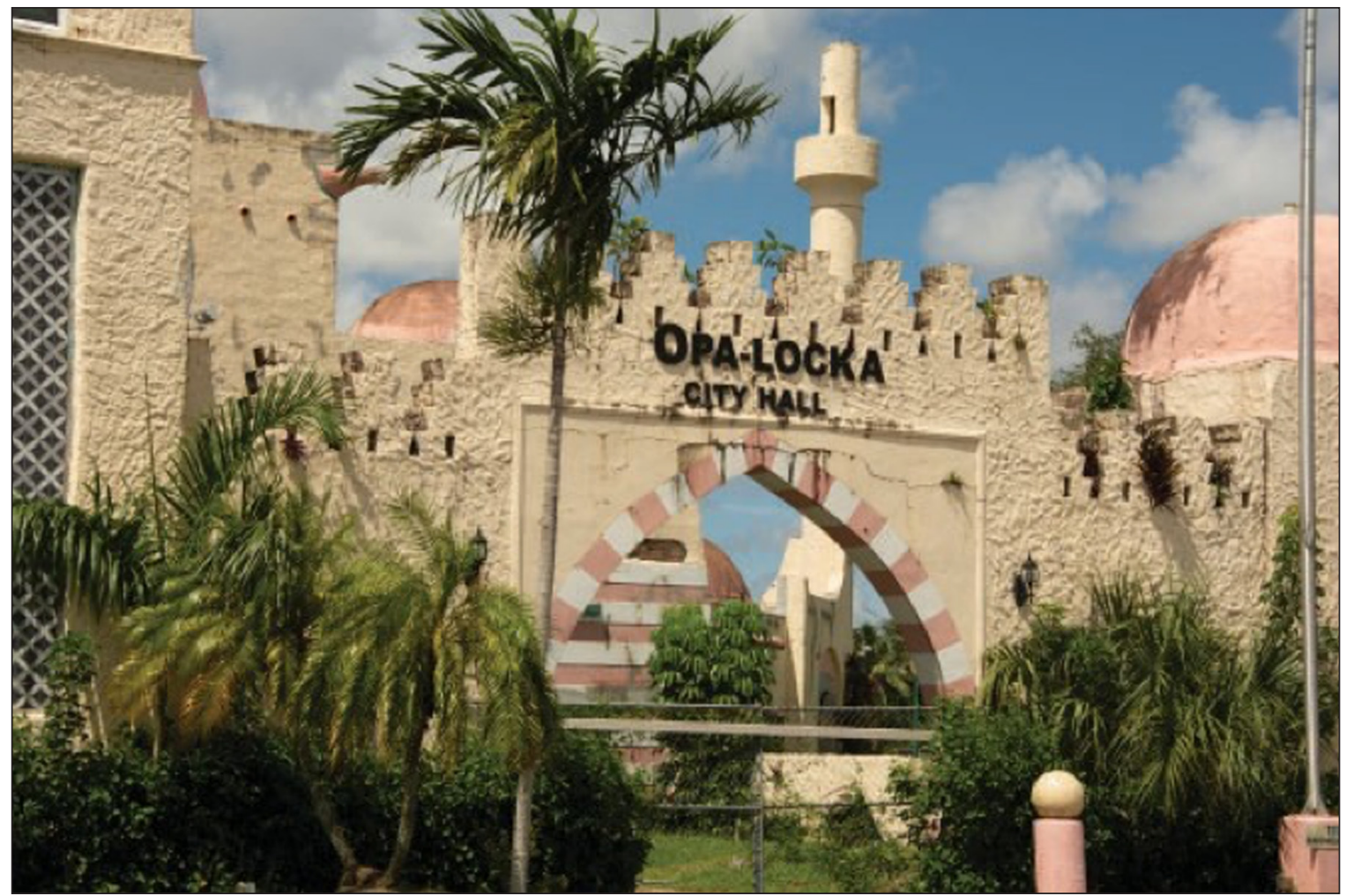

Opa-locka, FL, 2019.

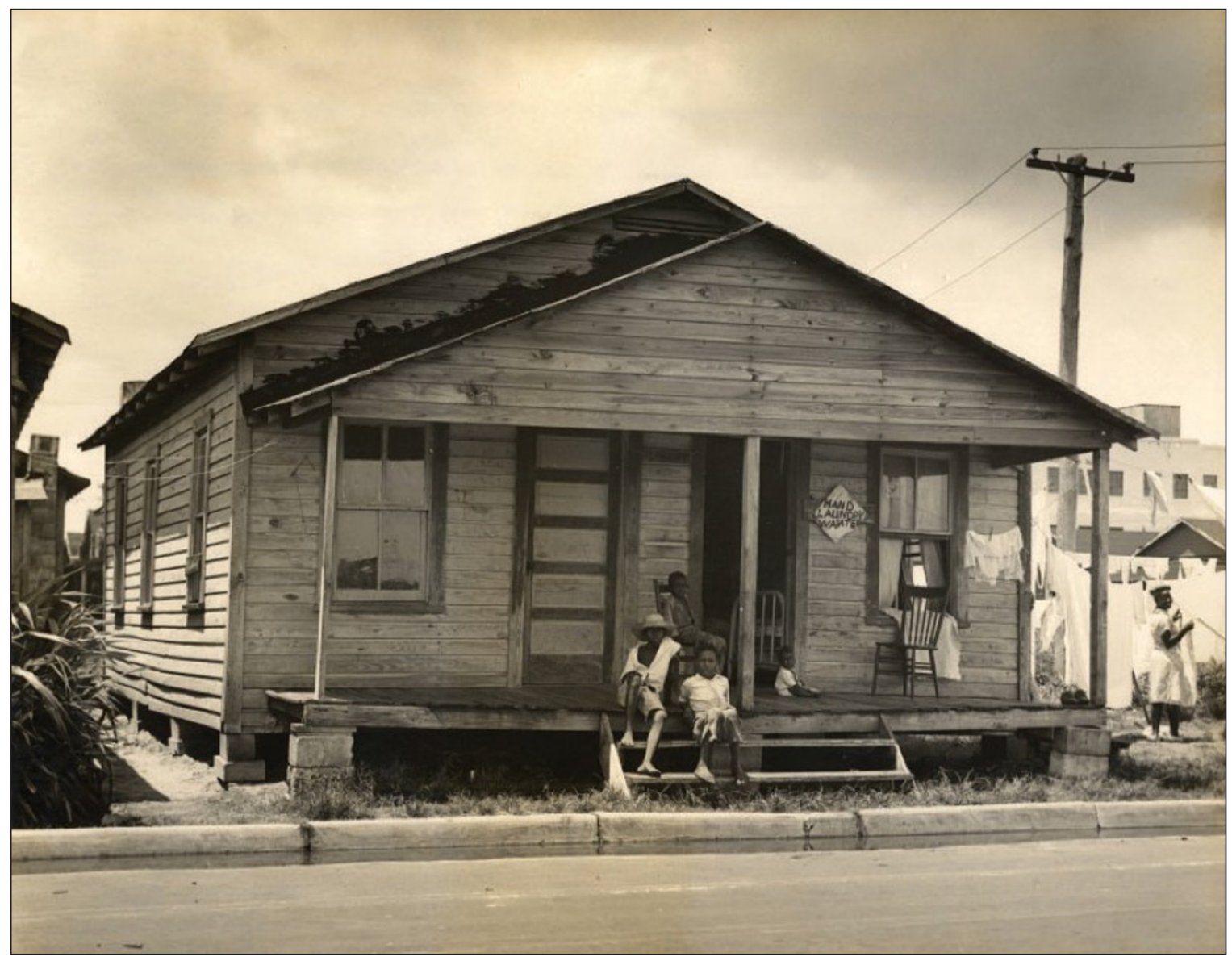

Overtown, Miami, FL. Image courtesy of HistoryMiami. 


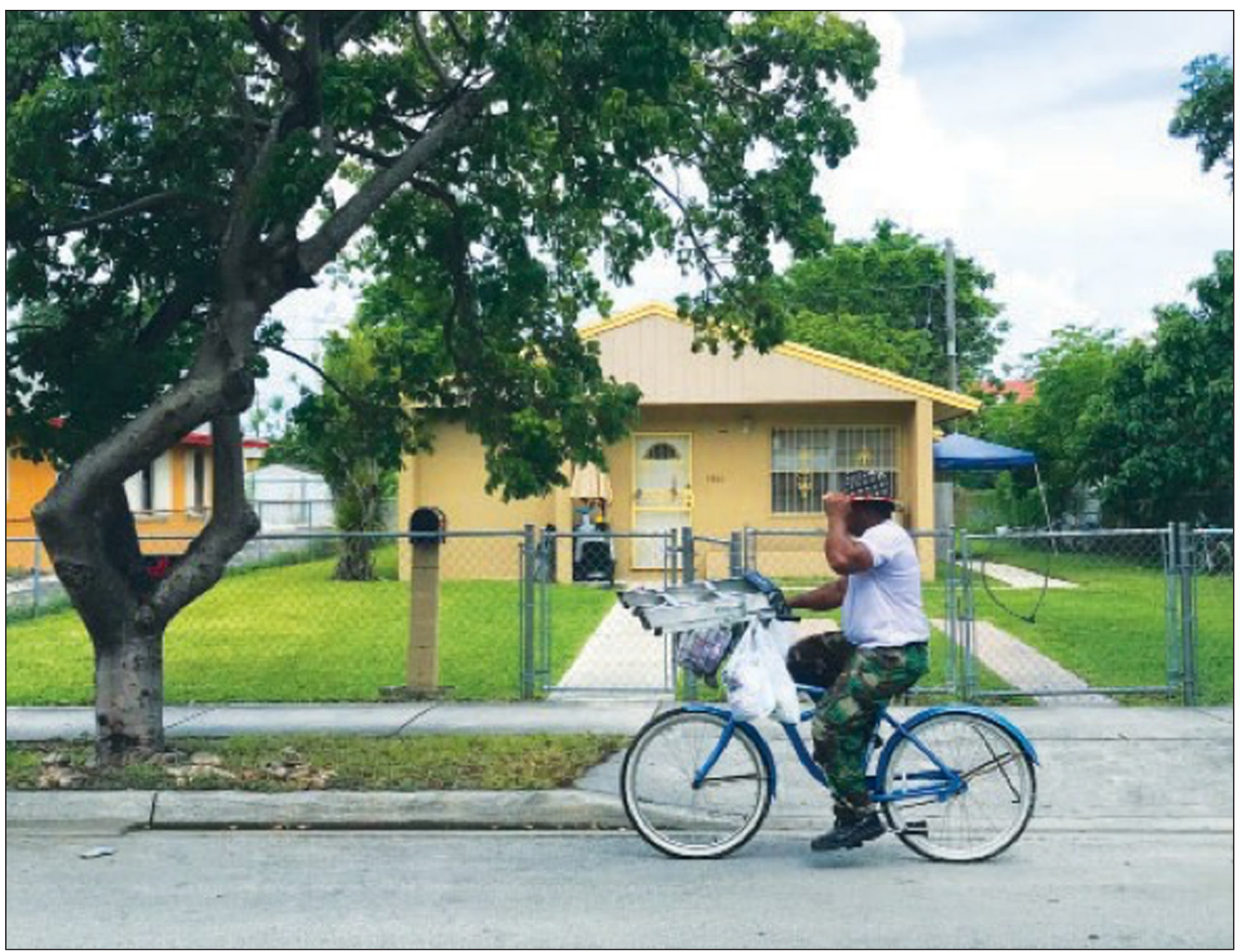

Overtown, Miami, FL, 2019.

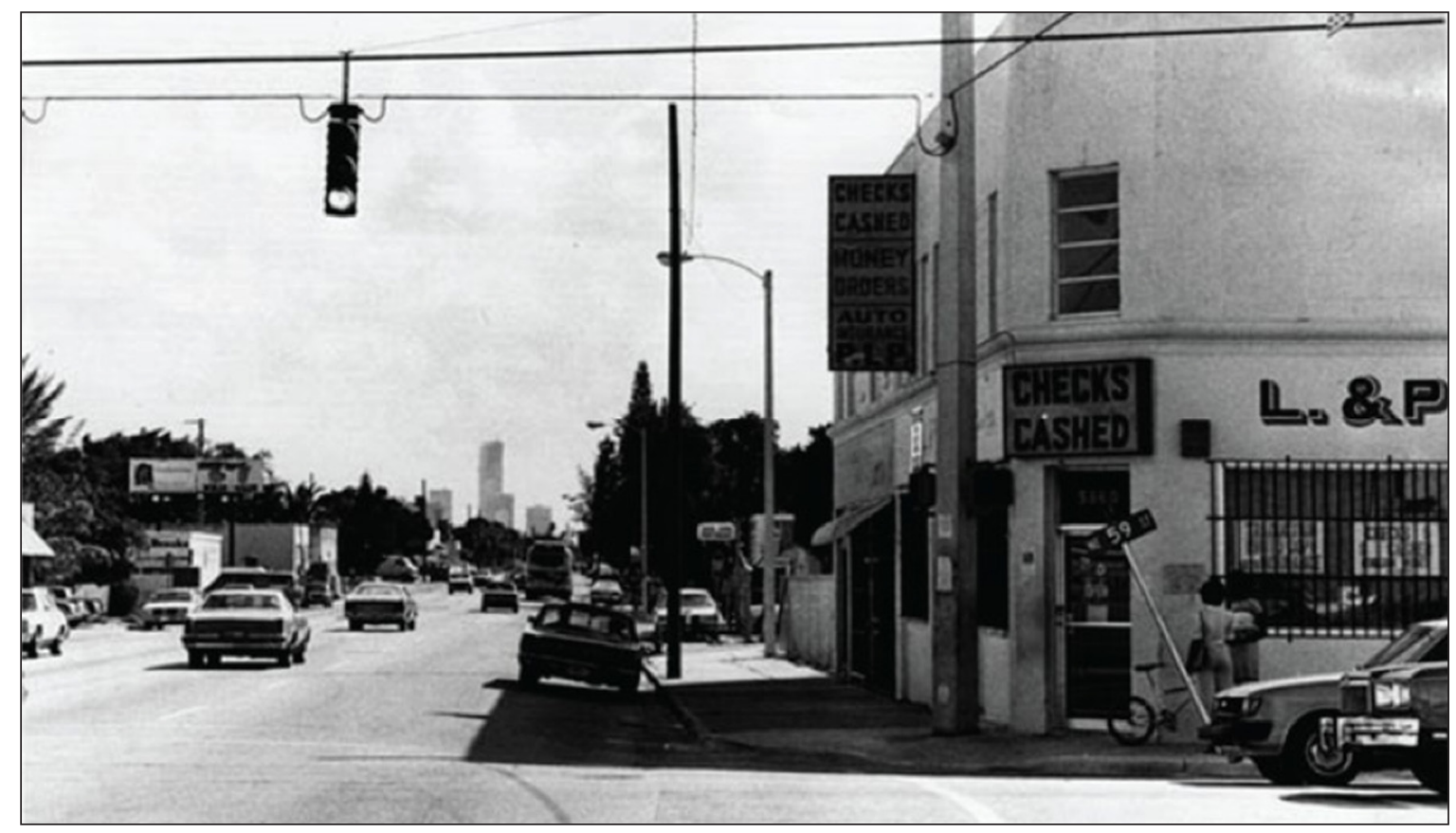

Little Haiti, Miami, FL, 1983. Image courtesy of HistoryMiami. 


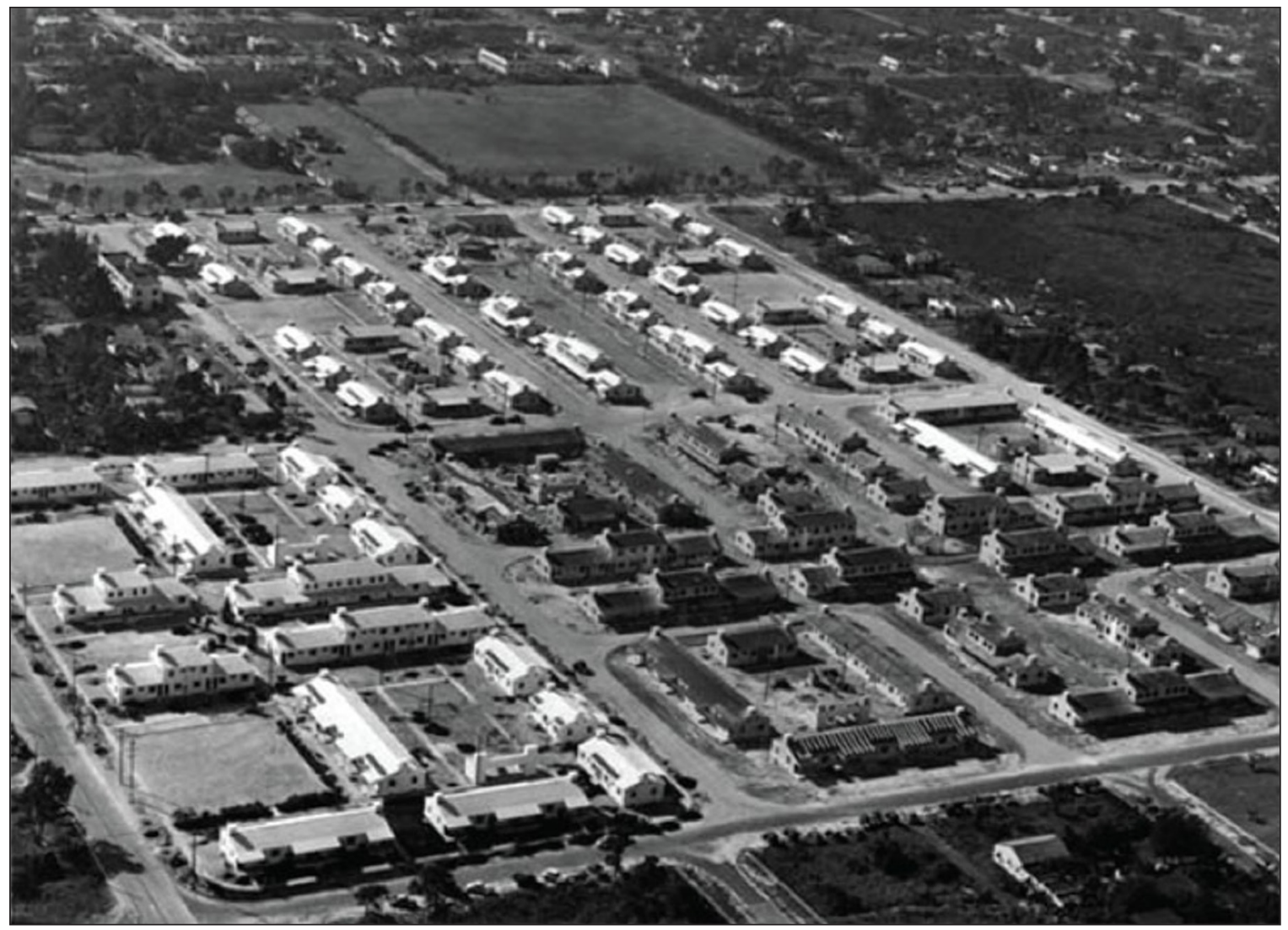

Edison Courts Little Haiti, Miami, FL, 1947. Image courtesy of HistoryMiami.

\section{Competing Interests}

The author has no competing interests to declare.

How to cite this article: Barnes, G 2020 Black Miami's Resiliency: A Photographic Essay. Anthurium, 16(1): 3, 1-8. DOI: https://doi.org/10.33596/anth.404

Published: 31 March 2020

Copyright: (c) 2020 The Author(s). This is an open-access article distributed under the terms of the Creative Commons Attribution 4.0 International License (CC-BY 4.0), which permits unrestricted use, distribution, and reproduction in any medium, provided the original author and source are credited. See http://creativecommons.org/licenses/by/4.0/. 